
\title{
25 Research Square \\ Intestinal Parasitic Infection and Its Associated Factors among Food Handlers in Ginnir Town, Bale Zone, Southeast, Ethiopia
}

\section{Asfaw Negero}

Madawalabu University

\section{Tomas Benti}

Madawalabu University

Solomon Taye ( $\nabla$ tayesolomon38@gmail.com )

University of Gondar https://orcid.org/0000-0001-6831-4733

\section{Research article}

Keywords: Prevalence, Intestinal parasites, Food handlers, Food borne disease, Associated factors

Posted Date: August 8th, 2020

DOI: https://doi.org/10.21203/rs.2.23709/v2

License: (c) (i) This work is licensed under a Creative Commons Attribution 4.0 International License.

Read Full License 


\section{Abstract}

Background: Intestinal parasitic infections are the most common infections in the developing world. Globally, out of the 1.5 billion annual cases of diarrhea, about $70 \%$ or 1.05 billion cases are thought to be caused by biological contamination of food. In Ethiopia, due to poor environmental sanitation, low awareness about personal hygiene, lack of pure potable water, and improper faecal disposal, intestinal parasitic infections are highly prevalent. Thus, the aim of this study was to determine the prevalence and associated factors of intestinal parasitosis among food handlers working in food and drinking establishments in Ginnir town, southeast, Ethiopia.

Methods: Cross-sectional study design was employed from May 1 to May 29, 2014 in food and drinking establishments in Ginnir town. A total of 348 food handlers were enrolled and stool specimens were collected, and examined using direct saline and formol-ether concentration methods. Bivariable and multivariable logistic regression analysis was performed. A P-value $<0.05$ was considered as an indicator of statistical significance.

Results: The overall prevalence of intestinal parasitosis among food handlers was 48/348 (13.8\%) [95\%, $\mathrm{Cl}=6.8-20.6]$. Entamoeba histolytica/dispar 23/348 (6.6\%) followed by Giardia lamblia 16/348 (4.6\%), Ascaris lumbricoides 7/348 (2.0\%) and Strongyloides stercolaris 2/348 (0.6\%) were the detected parasites. Moreover, amongst positives for intestinal parasites, comparable proportions of parasites were detected in males (52\%) and females (48\%). Habit of eating raw/under cooked vegetables $(p=0.00$; $\mathrm{aOR}=2.60 ; 95 \%, \mathrm{Cl}=1.94-8.67)$, hand washing habit before eating ( $\mathrm{p}=0.03 ; \mathrm{aOR}=1.22 ; 95 \%, \mathrm{Cl}=1.01-3.89)$, hand washing habit after visiting toilet $(\mathrm{p}=0.01$; $\mathrm{aOR}=2.85 ; 95 \%, \mathrm{Cl}=2.06-8.31)$, hand washing habit before food preparation $(p=0.02 ; a O R=1.85 ; 95 \%, C l=1.27-4.34)$ and poor personal hygiene $(p=0.00 ; a O R=3.39$; $95 \%, \mathrm{Cl}=1.51-10.23)$ were factors associated with intestinal parasitic infections.

Conclusions: The prevalence of intestinal parasitosis among food handlers was relatively low. Though the prevalence was low; regular medical check-up, training and health education on safe food handling and processing should be given to all food handlers.

\section{Introduction}

Intestinal parasitic infections are among the most common infections [1, 2]. It may cause serious public health problems because of the complications such as iron deficiency anaemia, growth retardation in children and other physical and mental health problems [3, 4]. Intestinal parasites are highly prevalent in developing countries including Ethiopiaprimarily due to; unsafe human waste disposal systems, inadequacy and lack of safe water supply, and low socio-economic status. In sub-Saharan African countries; up to 250 million people are estimated to be infected with at least one or more species of intestinal parasites [5].Food borne disease is any disease of an infectious or toxic nature caused by consumption of contaminated food [6, 7]. Food borne disease outbreak is the occurrence of two or more cases of a similar food borne disease resulting from the ingestion of a common food. Estimates had 
indicated that out of the 1.5 billion global annual cases of diarrhea, about $70 \%$ or 1.05 billion cases are thought to be caused by biological contamination in food $[8,9]$.Food can be contaminated by physical, chemical and microbiological agents. It may be contaminated by polluted water, flies, animals and pets, unclean utensils and pots, dust and dirt. However, the sources of food contamination are diverse. The microbial agents responsible for food borne diseases are bacteria, virus, parasites and fungi. More than 200 pathogens are associated with food borne disease. Parasites are responsible for the majority of food borne and/or water borne diseases particularly in developing countries including Ethiopia. Unhygienic food handlers can also inoculate the food with infected excreta, pus, respiratory droppings' or other infectious discharges $[9,10]$.Food service establishments are sources of food borne and/or water borne illnesses and food handlers contribute to food borne illness. Food handlers with poor personal hygiene and inadequate knowledge on food safety could be the source of food borne pathogens. i.e. unhygienic food handlers inoculate the food with infected excreta, pus, respiratory dropping or other infectious discharges [10-12]. In this regard, in Ethiopia, studies conducted on food handlers showed that, $A$. lumbricoides, E. histolytica/disparand G. lamblia are the main parasites to be detected [13-16]. Ginnir is one of the woredas in the Oromia region Bale Zone, Southeast Ethiopia. It is located $600 \mathrm{~km}$ from the capital Addis Ababa. At Ginnir town there are 132 food and drink establishments, 72 restaurants, 38 pensions, 17 hotels, and 5 café. In the present study area, although there are unpublished reports that shows intestinal parasitosis is high in the community, however, there is no data regarding the prevalence of intestinal parasitosis particularly among food handlers. Therefore, the objective of this study was to determine the prevalence and associated factors of intestinal parasitosis among food handlers in Ginnir town, southeast, Ethiopia

\section{Materials And Methods}

\section{Study design, population and sampling technique}

The study was conducted in Ginnir town, Bale zone, Oromia regional state, Southeast, Ethiopia from May 1 to May 29, 2014 in food and drinking establishments. During the study period, in food and drinking establishments there were 2350 workers/employee those who have direct or indirect contact with food. Cross-sectional study design was used and the sample size was determined using the single proportion population formula, taking the prevalence rate of intestinal parasites among food handlers in Bahirdar town, Northwest Ethiopia ( $P=41 \%$ ) [16], and the calculated sample size was 408 including $10 \%$ nonresponse rate. However, by considering the number of food handlers working in food establishments in the town $(<10,000)$ and thus, the final corrected sample size was 348 . Finally, study participants were selected proportionally from the establishments using simple random sampling method.

\section{Sample collection and laboratory analysis}

Qualitative data's were collected by face to face interview using a structured questionnaire after informed written consent was obtained from each participant. To ensure the reliability of data, participants were interviewed with their mother tongue. The questionnaire was designed to obtain information on socio- 
demographic characteristics of food handlers, availability of sanitary facilities like water supply, latrine facility, refuse management, food utensil washing facility and bathroom services, storage system of food and food utensils as well as to measure the awareness and practice of food handlers through observation and interview. During the interview, participants were inspected whether their finger nails were trimmed or not, their general hygienic situation, dirty materials on their hands, and their foot wears.

After the interview was completed, respondents were asked to bring 2-3gm of fresh stool specimen in a labeled clean plastic cup with a tight fitting lid. All the participants provided the stool specimen on site (in their work place) and samples were transported to the nearby health center. Direct saline stool examination and formol-ether concentration method were done by medical laboratory technologists within less than 30 minutes after collection. lodine staining was also prepared to identify cysts of protozoal parasites. All standard procedures strictly followed during stool sample examination to ensure the quality and sensitivity of the test result.

\section{Data analysis}

Data entry and analysis was done using SPSS version 16 computer software. Internal comparisons were made using logistic regression to determine the independent effect of the variables by calculating the strength of the association between infection and associated factors using odds ratio (OR) with $95 \%$ confidence interval $(\mathrm{Cl})$. Crude and adjusted OR were computed using bivariate and multivariable logistic regression analysis respectively. A p-value less than 0.05 was considered as statistically significant.

\section{Results}

\section{Socio-demographic characteristics of the participants}

A total of 348 food handlers were enrolled in this intestinal parasitosis prevalence study with zero nonresponse rate. The socio-demographic characteristics of the participants were presented in Table 1. One hundred seventy five (50.3\%) of the participants were female, resulting in the male to female ratio of 0.98:1. Majority of the study subjects $157 / 348(45 \%)$ were cookers, followed by waiters $141 / 348(40.5 \%)$, coffee/tea machine operators $21 / 348(6 \%)$ and utensil and left over food cleaners $16 / 348(4.6 \%)$ (Table 1).

Majority (118/348(33.9\%)) of the study subjects were within the interval of 15-19 years of age, followed by $20-24$ years of age interval $(115 / 348(33 \%))$. Furthermore, $188 / 348(54 \%)$ of the participants had educational level from grade $7-12$ and $143 / 348(41.1 \%)$ of them attended from grade 1-6 and only $6 / 348(1.7 \%)$ of the participants were studied above grade 12. As it's shown in Table 1, none of the sociodemographic variables were significantly associated with intestinal parasite infections $(p>0.05)$.

Table 1. Socio-demographic characteristics of food handlers in Ginnir town, Southeast Ethiopia, 2014. 


\begin{tabular}{|c|c|c|c|c|}
\hline \multicolumn{2}{|c|}{ Characteristics } & \multirow{2}{*}{$\begin{array}{l}\text { Total n(\%) } \\
173(49.7 \%)\end{array}$} & \multirow{2}{*}{\begin{tabular}{|l|} 
No of positive for intestinal \\
parasitosis (\%)
\end{tabular}} & \multirow{2}{*}{$\begin{array}{l}\mathbf{p -} \\
\text { value } \\
0.723\end{array}$} \\
\hline Sex & Male & & & \\
\hline & Female & $\begin{array}{l}175 \\
(50.3 \%)\end{array}$ & $23(48 \%)$ & \\
\hline \multirow[t]{6}{*}{ Job } & Waiter & $\begin{array}{l}141 \\
(40.5 \%)\end{array}$ & $19(39.6 \%)$ & \multirow[t]{6}{*}{0.730} \\
\hline & Cooker & $157(45 \%)$ & $23(48 \%)$ & \\
\hline & Coffee/tea machine operator & $21(6 \%)$ & $4(8.3 \%)$ & \\
\hline & House cleaner & $8(2.3 \%)$ & 0 & \\
\hline & $\begin{array}{l}\text { Utensil and left over food } \\
\text { cleaner }\end{array}$ & $16(4.6 \%)$ & $2(4.2 \%)$ & \\
\hline & Others & $5(1.4 \%)$ & 0 & \\
\hline \multirow[t]{3}{*}{ Religion } & Muslim & $162(46.6 \%)$ & $25(52 \%)$ & \multirow[t]{3}{*}{0.707} \\
\hline & Orthodox & $136(39.1 \%)$ & $17(35.4 \%)$ & \\
\hline & Protestant & $50(14.6 \%)$ & $6(12.5 \%)$ & \\
\hline \multirow[t]{5}{*}{ Age interval } & $10-14$ & $12(3.4 \%)$ & 0 & \multirow{5}{*}{0.066} \\
\hline & $15-19$ & $118(33.9 \%)$ & $16(33.3 \%)$ & \\
\hline & $20-24$ & $115(33 \%)$ & $21(43.8 \%)$ & \\
\hline & $25-29$ & $61(17.5 \%)$ & $10(20.8 \%)$ & \\
\hline & $30-35$ & $42(12.1 \%$ & $1(2.1 \%)$ & \\
\hline \multirow{4}{*}{$\begin{array}{l}\text { Educational } \\
\text { status }\end{array}$} & Illiterate & $11(3.2 \%)$ & $4(8.3 \%)$ & \multirow{4}{*}{0.104} \\
\hline & $1-6$ & $143(41.1 \%)$ & $21(43.8 \%)$ & \\
\hline & $7-12$ & $188(54 \%)$ & $23(49.9 \%)$ & \\
\hline & $12+$ & $6(1.7 \%)$ & 0 & \\
\hline
\end{tabular}

\section{Prevalence of intestinal parasitosis}

Based on microscopic stool sample examination results, four species of intestinal parasites were identified and thus, the overall prevalence of intestinal parasites among food handlers was 48/348(13.8\%). The commonest parasites to be detected were, Entamoeba histolytica/dispar 23/348(6.6\%) followed by Giardia lamblia 16/348(4.6\%), Ascaris lumbricoides 7/348(2.0\%) and 
Strongyloides stercolaris $2 / 348(0.6 \%)$. All these parasites were found as a mono-infection, however, no double, triple and quadruple parasitic infections were detected. Furthermore, the prevalence of intestinal parasites in males and females was comparable (52\% Vs $48 \%$ respectively) (Table 2 ).

Table 2. Type of intestinal parasite identified among food handlers in Ginnir town, Southeast Ethiopia, 2014.

\begin{tabular}{|l|l|l|}
\hline Type of intestinal parasite & $\begin{array}{l}\text { Total positive for intestinal } \\
\text { parasitosis } \mathbf{n}(\%)\end{array}$ & $\begin{array}{l}\text { Prevalence among detected parasites } \\
\mathbf{n}(\%)\end{array}$ \\
\hline $\begin{array}{l}\text { Entamoeba } \\
\text { histolytica/dispar }\end{array}$ & $23(6.6)$ & $23(47.9)$ \\
\hline Giardia lamblia & $16(4.6)$ & $16(33.3)$ \\
\hline Ascaris lumbricoides & $7(2.0)$ & $7(14.6)$ \\
\hline Strongyloides stercolaris & $2(0.6)$ & $2(4.2)$ \\
\hline
\end{tabular}

\section{Factors associated with intestinal parasitosis}

The distributions of intestinal parasites and associated factors were indicated in Table 3. Habit of eating raw/under cooked vegetables ( $A O R=6,95 \% \mathrm{Cl}=2.94-8.67$ ) and poor personal hygiene (As described by: dirty materials on hand/body, dirt in finger nails, unclean hair, dirty clothes, those don't have regular bath, no/dirty shoes) were associated factors that showed statistically significant association with intestinal parasitosis ( $A O R=39,95 \% \mathrm{Cl}=1.51-10.23)$. Three hundred twenty five $(93.4 \%)$ of the study subjects did not attended any training on how to safely process food and awareness on food hygiene and $328(94.3 \%)$ of the participants were responded that they always wash their hands before eating. However, both showed no significant association with parasitic infections ( $A O R=56,95 \% \mathrm{Cl}=0.61-5.11)$ and $(A O R=1.10,95 \%$ $\mathrm{Cl}=0.55-1.62)$ Furthermore, even though it lacks statistically significant association, intestinal parasitosis was higher in those who have no regular medical checkup ( $A O R=56,95 \% \mathrm{Cl}=0.75-3.15)$ and those wear protective coat during cooking ( $\mathrm{AOR}=50,95 \% \mathrm{Cl}=0.87-4.35)$ (Table 3 ).

Table 3. Multivariable analysis of factors associated with intestinal parasitosis among food handlers in Ginnir town, Southeast, Ethiopia, 2014. 


\begin{tabular}{|c|c|c|c|c|c|}
\hline \multicolumn{2}{|l|}{ Characteristics } & \multirow{2}{*}{$\begin{array}{l}\text { Total n(\%) } \\
314(90.2 \%)\end{array}$} & \multirow{2}{*}{$\begin{array}{l}\text { No of positive for intestinal } \\
\text { parasitosis (\%) }\end{array}$} & \multirow{2}{*}{\begin{tabular}{|l|}
$\begin{array}{l}\text { Adjusted OR } \\
(95 \% \mathrm{CI})\end{array}$ \\
$1.24[0.85-$ \\
$1.98]$
\end{tabular}} & \multirow{3}{*}{\begin{tabular}{|l|}
$P-$ \\
value \\
0.871
\end{tabular}} \\
\hline Ever heard about hygiene & Yes & & & & \\
\hline & No & $34(9.8 \%)$ & $5(10.4 \%)$ & 1 & \\
\hline \multirow[t]{2}{*}{$\begin{array}{l}\text { Hand washing habit before } \\
\text { eating }\end{array}$} & Always & $328(94.3 \%)$ & $45(93.6 \%)$ & $\begin{array}{l}1.10[0.55- \\
1.62]\end{array}$ & \multirow[t]{2}{*}{0.871} \\
\hline & Almost & $20(5.7 \%)$ & $3(6.3 \%)$ & 1 & \\
\hline \multirow[t]{2}{*}{ Hand washing habit after toilet } & Always & $304(87.4 \%)$ & $46(95.8 \%)$ & $\begin{array}{l}1.37[0.63- \\
3.25]\end{array}$ & \multirow[t]{2}{*}{0.057} \\
\hline & Almost & $44(12.6 \%)$ & $2(4.2 \%)$ & 1 & \\
\hline \multirow[t]{2}{*}{$\begin{array}{l}\text { Hand washing habit before food } \\
\text { preparation }\end{array}$} & Always & $291(83.6 \%)$ & $37(77.1 \%)$ & $\begin{array}{l}1.66[1.01- \\
2.95]\end{array}$ & \multirow[t]{2}{*}{0.187} \\
\hline & Almost & $57(16.4 \%)$ & $11(22.9 \%)$ & 1 & \\
\hline \multirow[t]{2}{*}{$\begin{array}{l}\text { Habit of eating raw/under } \\
\text { cooked vegetables }\end{array}$} & Yes & $144(41.4 \%)$ & $34(70.8 \%)$ & $\begin{array}{l}2.6[2.94- \\
8.67]\end{array}$ & \multirow[t]{2}{*}{0.000} \\
\hline & No & 204(58.6\%) & $14(29.2 \%)$ & 1 & \\
\hline \multirow[t]{2}{*}{ Habit of regular finger trimming } & Yes & $308(88.5 \%)$ & $40(83.3 \%)$ & $\begin{array}{l}1.65[0.90- \\
5.22]\end{array}$ & \multirow[t]{2}{*}{0.226} \\
\hline & No & $40(11.5 \%)$ & $8(16.7 \%)$ & 1 & \\
\hline \multirow[t]{3}{*}{ Personal hygiene } & Good & $176(50.6 \%)$ & $11(22.9 \%)$ & $\begin{array}{l}3.39[1.51- \\
10.23]\end{array}$ & \multirow[t]{3}{*}{$\begin{array}{l}0.000 \\
0.001\end{array}$} \\
\hline & Fair & $152(43.7 \%)$ & $23(47.9 \%)$ & $\begin{array}{l}2.17[0.99- \\
9.97]\end{array}$ & \\
\hline & Poor & $20(5.7 \%)$ & $14(29.2 \%)$ & 1 & \\
\hline \multirow[t]{2}{*}{$\begin{array}{l}\text { Training on safe food processing } \\
\text { and hygiene }\end{array}$} & Yes & $23(6.6 \%)$ & $2(4.2 \%)$ & $\begin{array}{l}0.56[0.61- \\
5.11]\end{array}$ & \multirow[t]{2}{*}{0.463} \\
\hline & No & $325(93.4 \%)$ & $46(95.8 \%)$ & 1 & \\
\hline \multirow[t]{2}{*}{ Regular medical check up } & Yes & $39(11.2 \%)$ & $4(8.3 \%)$ & $\begin{array}{l}1.56[0.75- \\
3.15]\end{array}$ & \multirow[t]{2}{*}{0.497} \\
\hline & No & $309(88.8 \%)$ & $44(91.7 \%)$ & 1 & \\
\hline
\end{tabular}




\begin{tabular}{|c|c|c|c|c|c|}
\hline \multirow[t]{2}{*}{$\begin{array}{l}\text { Habit of wearing protective coat } \\
\text { during cooking }\end{array}$} & Yes & $150(43.1 \%)$ & $16(33.3 \%)$ & $\begin{array}{l}1.50[0.87- \\
4.35]\end{array}$ & \multirow[t]{2}{*}{0.141} \\
\hline & No & 198(56.9\%) & $32(66.7 \%)$ & 1 & \\
\hline
\end{tabular}

In addition, food handlers those always wash their hands after visiting toilet was took the higher proportion of intestinal parasitic infections even though not showed statistical significance (AOR=1.37, $95 \% \mathrm{Cl}=63-3.25)$. The remaining associated factors like; habit of regular finger trimming, ever heard about hygiene and hand washing habit before food preparation had showed no statistical association with intestinal parasitic infections ( $p>0.05$ ) (Table 3 ).

\section{Discussion}

Intestinal parasitic infections are the commonest infections worldwide. The overall prevalence of parasitic infections $48 / 348(13.8 \%)$ in this study is lower than other studies done on food handlers in Gondar Ethiopia (25\%) [13], Jimma Ethiopia (58.4\%) [15], Bahirdar Ethiopia (41\%) [16]and Gaza strip (24.3\%) [19].

The low prevalence in this study could be explained due to; possible geographical variation of the study areas and its impact on the prevalence of intestinal parasite, socio-economic and cultural differences of study subjects or may be due to the fact that the present study participants may have better information regarding personal hygiene. On the other hand, it is higher than prevalence study in Iran (11.9\%) [17] and Omdurman area of Sudan (6.9\%) [18].

In this study, histolytica/dispar 23/348(6.6\%) is the leading protozoal parasite among food handlers in Ginnir town which is in consistent with the study conducted in Gondar Ethiopia (6\%) [13]. However, it is much lower than when it compared with histolytica/dispar prevalence (19.2\%) among food handlers in Gaza strip [19]. High prevalence of histolytica/dispar Gaza strip was due to low sanitary condition, contamination of drinking water or vegetables. The high prevalence may also be due to histolytica over diagnosis because of absence of molecular based diagnosis to differentiate histolytica from E. dispar or may be a reflection of the local endemicity of histolytica in Gaza strip. The higher prevalence in this study is might be because of contamination of drinking water and vegetables and fruits.

lamblia 16/348(4.6\%) was the second most prevalent intestinal protozoa in this study. In this study, it is lower than the study conducted in Gondar Ethiopia which showed a prevalence of 11\% [13] and other countries; Omdurman area of Sudan (20.5\%) [18]. In contrast, it is higher than one study conducted in Iran (3.7\%) [17]. The higher prevalence in this study is might be because of contamination of drinking water and vegetables and fruits. The magnitude of other intestinal parasitic infections in this study varies and/or comparable with other study areas. The differences in prevalence rate between the study 
areas might be due to culture, practice, living standard and category of the study population in addition to the period of study and the methods employed for stool examination.

In the present study, habit of eating raw/under cooked vegetables and poor personal hygiene (As described by: dirty materials on hand/body, dirt in finger nails, unclean hair, dirty clothes, those don't bath, no/dirty shoes) were significantly associated with intestinal parasitosis which is in line with other studies done in Gondar Ethiopia, Mekelle Ethiopia, Jimma Ethiopia and Bahirdar Ethiopia [13-16].

In addition, $4 \%$ of food handlers replied they always wash their hands after visiting toilet while the rest $6 \%$ didn't. Furthermore, majority of food handlers $(9 \%)$ had no regular medical check-up including stool examination. Even though they were not significant, however, given larger number of participants, they may have significant association with intestinal parasitosis. These finding are in consistent with the study done by Teferi MD et al. [13] in Gondar Ethiopia indicating $89.5 \%$ food handlers had the habit of hand washing after toilet visit and $5 \%$ of the study participants had no medical check-up at all. These studies were clearly indicated that, there is a visible gap between knowledge and practice regarding transmission of parasites among the community i.i.e, people know how parasites are transmitted and their effect on health; however, they are not correctly practicing transmission control mechanisms to halt parasite infections.

\section{Conclusion}

The prevalence of intestinal parasites among food handlers in food and drink establishments in Ginnir town is relatively low. However, safe food handling practice and personal hygiene of food handlers is poor. Therefore, training on safe food handling and processing and regular medical check-up are highly recommended for the food handlers. Regular inspection of the establishments regarding food storage system, availability of clean water, clean toilet and waste disposal system by regulatory body is also recommended.

\section{Declarations}

\section{Ethics approval and consent to participate}

The study was approved by the Research Ethics and Review Committee of Madawalabu University. Permission was also obtained from of Ginnir town administration and health bureau. The owners of the establishments were informed about the objectives of the study. Participants recruited to the study were clearly informed about the objectives of the study and the benefits of participation. Participation was fully on voluntary basis and informed written consent was obtained from each participant for his/her participation prior to sample collection. Signed assent was obtained from parents for child participants. For each confirmed positive cases, appropriate treatment was given by nurses free of charge. The data's of the participants was manipulated only by investigators and kept confidential by numeric coding of samples and questionnaires. 


\section{Consent to publish}

Not applicable

\section{Availability of data and materials}

All data generated during this study are included in this article.

\section{Competing Interests}

As authors, we declare that, we have no any competing interests.

\section{Funding}

The research is funded by Madawalabu University

\section{Authors' Contribution}

All authors equally contributed to this work. All the authors' read and approved the manuscript.

\section{Acknowledgments}

We would like to thank Madawalabu University Research and Community Services Directorate office. We would like to acknowledge study participants, owners of food and drink establishments, Ginnir town administration and health bureau. We are also grateful to the medical laboratory technologists and nurses who participated in laboratory diagnosis and treating positive cases. Lastly, our gratitude goes to our friends and colleagues for their constructive comments and advice.

\section{Author Information}

${ }^{1}$ Department of Microbiology, Immunology and Parasitology, College of Medicine and Health Sciences, Madawalabu University, E-mail: asfneg@yahoo.com, Bale Goba, Ethiopia. ${ }^{2}$ Department of Nursing, College of Medicine and Health Sciences, Madawalabu University, E-mail: thomas_benti@yahoo.com, Bale Goba, Ethiopia. ${ }^{3 *}$ Department of Microbiology, Immunology and Parasitology, College of Medicine and Health Sciences, Wachemo University, E-mail: tayesolomon38@gmail.com, Hossana, Ethiopia.

\section{References}

1. Kongs A, Marks G, Verle P, Van Der, Stuyft P. The Unreliability of the Kato-Katz Technique limits its Usefulness for Evaluating mansoni Infections. Trop. Med. Inter Heal; 2001, 163-169.

2. Mengistu A, Gebre-Selassie S, Kassa T. Prevalence of intestinal parasitic infections among urban dwellers in southwest Ethiopia. J. Heal. Dev, 2007, 21(1):12-17.

3. Bankae ROK, Omudu EA, Ikenwa DA, Feese IJ. Prevalence of gastro-intestinal parasites in relation to availability of sanitory facilities among schooling children in Makurdi, Nigeria. Res. Int, 2006, 
3(2):489-493.

4. Al-Mohammed HI, Amin TT, Aboulmagd E, Hablus HR, Zaza BO, Al-Mohammed HI. Prevalence of intestinal parasitic infections and its relationship with socio-demographics and hygienic habits among male primary schoolchildren in Al-Ahsa, Saudi Arabia. Asian Pac. J .Trop. Med, 2010, 3(11):906-912.

5. World Health Organization. Prevention and control of schistosomiasis and soil-transmitted helminthiasis. WHO technical report series 912. WHO; 2002, Geneva, Switzerland.

6. World Health Organization. Foodborne Disease Outbreak: Guidelines for Investigation and Control. WHO; 2002. http://www.who.int/whr/2008.

7. World Health Organization. Food borne Disease: A focus for Health Education. WHO; 2000, Geneva, Switzerland.

8. Hailemariam T. and Demisse A. Livestock Marketing Authority: A paper presented on the occasion of the national food safety conference. 2002, Addis Ababa, Ethiopia.

9. World Health Organization. Food Safety: Food borne Diseases and value chain management for food safety. "Forging links between Agriculture and Health" CGIAR on Agriculture and Health Meeting in WHO/HQ. 2007, Geneva, Switzerland.

10. Stewart, G.F. Introduction to Food Science and Technology, Academic Press, 1997, New York, NY and London.

11. World Health Organization. Food safety as public health issue for developing countries. WHO; 2003, Geneva, Switzerland.

12. Rippel, B. Consumer knowledge about food safety: A paper presented on annual conference. 2002, Washington DC, USA.

13. Teferi MD, Wube MT, Yehuala FM. and Mehari ZT. Survey of nasal carriage of Staphylococcus aureus and intestinal parasites among food handlers working at Gondar University, Northwest Ethiopia. BMC Public Heal; 2012, 12(1): 837.

14. Araya Gebreyesus, Kelemework Adane, Letemichael Negash, Tsehaye Asmelash, Shwaye Belay, Megbaru Alemu and Muthupandian Saravanan. Prevalence of Salmonella typhi and intestinal parasites among food handlers in Mekelle University student cafeteria, Mekelle, Ethiopia. Elsevier Food Control; 2014, (44): 45-48.

15. Sahlemariam Z. and Mekete G. Examination of fingernail contents and stool for ova, cyst and larva of intestinal parasites from food handlers working in student cafeterias in three Higher Institutions in Jimma. Ethiopian J Health Sci; 2001, 11(2):131-137.

16. Abera B, Biadegelgen F. and Bezabih B. Prevalence of Salmonella typhi and intestinal parasites among food handlers in Bahir Dar Town, Northwest Ethiopia. Ethiop J Heal Dev; 2010, 24(1):46-50.

17. Kheirandish F, Badparva E. and Tarahi MJ. Prevalence of Intestinal Parasites in Bakery Workers in Khorramabad, Lorestan Iran. Iranian J. Parasitol; 2011, 6(4):76-83. 
18. Humodi Ahmed Saeeda and Hatim Hassan Hamid. Bacteriological and Parasitological Assessment of Food Handlers in the Omdurman Area of Sudan. Microbiol. Immunol. Infect, 2010, 43(1):70-73.

19. Adnan Al-Hindi et al. Occurrence of Intestinal Parasites and Hygiene Characters among Food Handlers in Gaza Strip, Palestine. Annals of Alquds Med;2012, 8: 2-13. 